American Journal of Agricultural and Biological Sciences 3 (4): 686-688, 2008

ISSN 1557-4989

(C) 2008 Science Publications

\title{
Laboratory Investigation of the Biology of Bactericera tremblayi Wag. (Homoptera: Triozidae) a New Pest in Onion Fields of Iran
}

\author{
Mohammad Hossein. Kazemi and Mohammad Mashhadi Jafarloo \\ ${ }^{1}$ Department of Plant Protection, Faculty of Agriculture, \\ Islamic Azad University, Tabriz branch, Tabriz, Iran \\ ${ }^{2}$ Department of Plant Pests and Diseases, \\ Agricultural and Natural Resources Research Center of East Azarbaijan, Tabriz, Iran
}

\begin{abstract}
Problem Statement: Psyllids as a small group of insects with plant feeding adult and nymphal stages, not only could have direct feeding damages but they could also transmit plant diseases especially viruses. Bactericera tremblayi had recently increased to high densities in onion fields in East Azarbaijan province in Iran and the pest had become widespread. This was the first study of the biology of the pest in Iran and probably in the world. Approach: After collection of the adult insects from infested onion fields, they were then reared in laboratory under controlled conditions (at $21 \pm 3^{\circ} \mathrm{C}$, $60 \pm 10 \%$ RH and under a 14:10 (L: D) light regime) and different life stages of the pest were studied. Results: The lifespan of adult male and female psyllids was $33.63 \pm 2.36$ and $39.94 \pm 2.64$ days respectively. The preoviposition period was $3.75 \pm 0.14$ days. The total number of eggs laid per female was $625.5 \pm 53.9$. Egg incubation took $7.44 \pm 0.15$ days and a mean of $90.3 \%$ eggs hatched. The nymphs passed through five instars before reaching the adult stage and the development time for the nymphal stage was $17.71 \pm 0.61$ days. The sex ratio was estimated as 1:1. Conclusions: The results of the present study could successfully be applied to future IPM strategies in order to effectively control this pest with relatively unknown biological characteristics and decrease the damages observed in onion fields.
\end{abstract}

Key words: Life-history, psyllids, onion fields

\section{INTRODUCTION}

Onion (Allium cepa L.) is one of the most important crops in Iran, especially in East Azarbaijan province. About 10,000 ha of onion are cultivated in the province, using an Iranian native variety (Azarshahr), with an average yield of $40 \mathrm{t} / \mathrm{ha}$. Due to the application of chemical pesticides against onion thrips, the most important and dominant pest in onion fields, the natural balance of the insect fauna has changed. As a result, the population of onion psyllid (Bactericera tremblayi) has increased. During this investigation, the largest infestations of psyllids were observed in onion fields in the Tabriz region. The taxonomy of the insect was investigated by Klimaszewski and Lodos ${ }^{[6]}$, Annunziata et al. ${ }^{[1]}$, Hodkins ${ }^{[4]}$ and Burckhardt and Lauterer ${ }^{[2]}$. It was first reported in Iran by Hassan Zadeh ${ }^{[3]}$ as part of the insect fauna of onion fields of East Azarbaijan province. Before developing an IPM (Integrated Pest Management) programme for this pest, it was necessary to study its morphology and biology. The biological study by Kazemi and Jafarloo ${ }^{[5]}$ of the insect in Iran is probably the first in the world. The identification of
Bactericera tremblayi Wag. was confirmed by $\mathrm{D}$. Burckhardt of the Natural History Museum in Basel, Switzerland.

\section{MATERIALS AND METHODS}

Plant and insect culture: Seeds of the Iranian native red variety of onion Azarshahr were sown in $15 \mathrm{~cm}$ diam. plastic pots at a depth of $2 \mathrm{~cm}$ and thinned to one plant per pot after germination. The soil was a mixture of field soil, compost and manure, this soil and the onion seeds were obtained from the Agricultural Research Center of East Azarbaijan. Psyllid nymphs were collected from infested onion fields and maintained under controlled conditions (see below) to provide a stock culture.

Infestation of plants: The insects were maintained in a growth chamber at $21 \pm 3^{\circ} \mathrm{C}, 60 \pm 10 \% \mathrm{RH}$ and $14: 10$ (L: D) light regime (Fig. 1).

For the main experiments, one adult male and one adult female were kept together in a glass jar and the

Corresponding Author: Mohammad Hossein Kazemi, Department of Plant Protection, Faculty of Agriculture,

Islamic Azad University, Tabriz branch, Tabriz, Iran Tel: +98 4116374511 Fax: +98 4116374511 


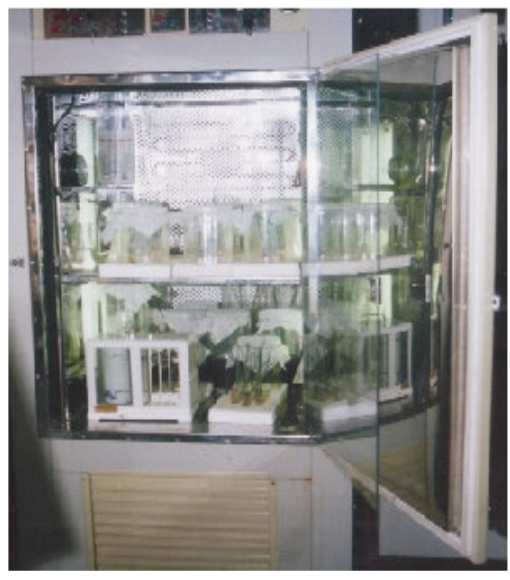

Fig. 1: Infested plants kept under controlled conditions inside the growth-chamber

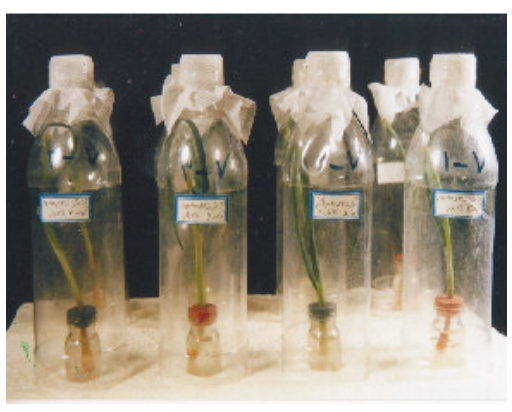

Fig. 2: Individual experimental plants inside separated containers for daily assessment

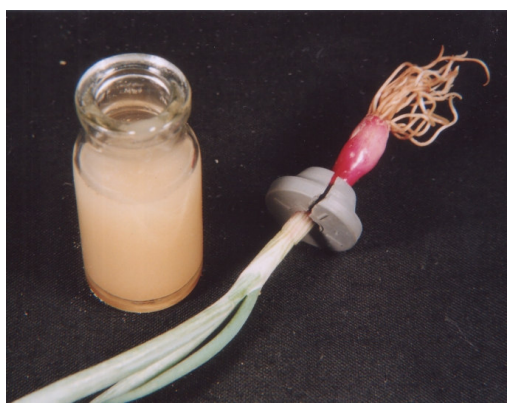

Fig. 3: Changing onion plants every day

female was allowed to lay eggs on the leaves of an onion plant which was removed from its pot and placed in the jar with its roots in a container with water inside the jar (Fig. 2). There were 20 replicate individual glass jars. Adult lifespan, the pre-oviposition period, total number of eggs, egg incubation time, percentage egg hatch, number of nymphal instars, nymphal development time and sex ratio were evaluated in each jar. To achieve this, the onion plants inside the jars were changed daily for a period of 70 days (Fig. 3).

\section{RESULTS}

The data obtained in this study clarify many aspects of the biology of this pest, especially as there are no similar studies, either in Iran or elsewhere, with which to make comparisons. Clearly these results will provide a basis for future studies, particularly in the context of the development of IPM strategies.

\section{DISCUSSION}

The lifespan of adult male (Fig. 4) and female (Fig. 5) psyllids (Mean \pm SE) was $33.63 \pm 2.36$ and $39.94 \pm 2.64$ days respectively. A t-test gave the small $t$ value of 0.44 , showing that these longevities were not significantly different.

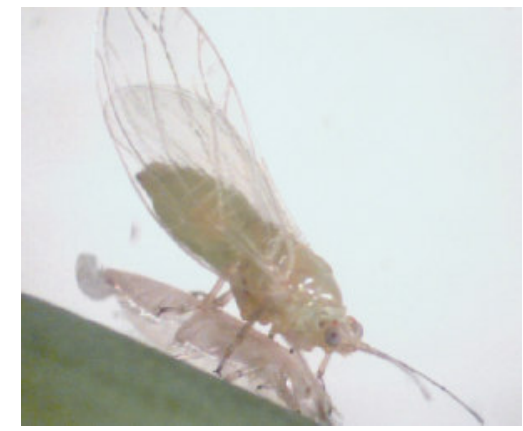

Fig. 4: Adult male insect

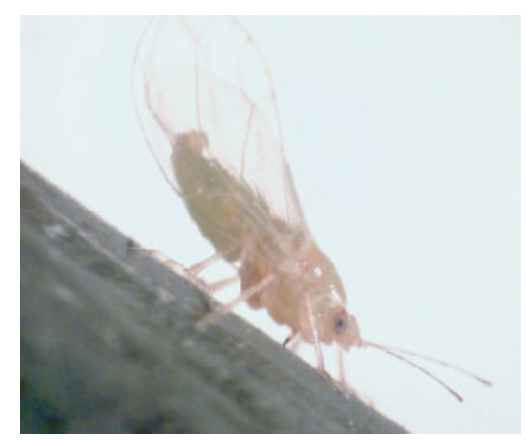

Fig. 5: Adult female insect, compare the end of the abdomen (genitalia) with that of the male insect

The pre-oviposition period was $3.75 \pm 0.14$ days. Eggs are stalked (Fig. 6), which is not uncommon with psyllids. The total number of eggs laid by a female was 


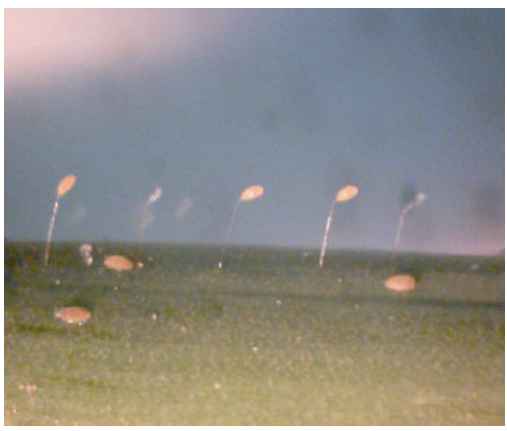

Fig. 6: Stalked eggs of psyllids and first instar nymphs on the leaf

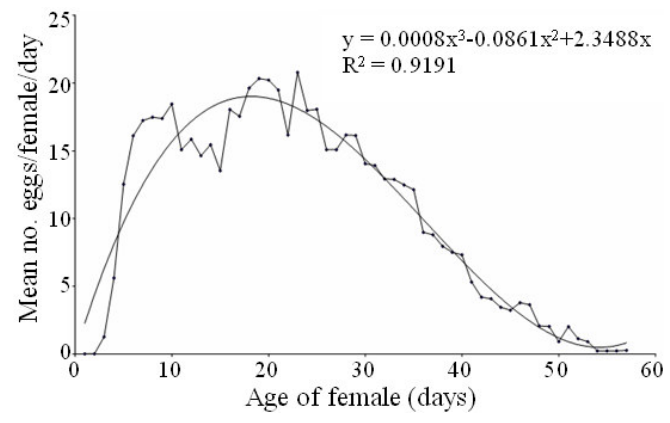

Fig. 7: Mean daily oviposition pattern

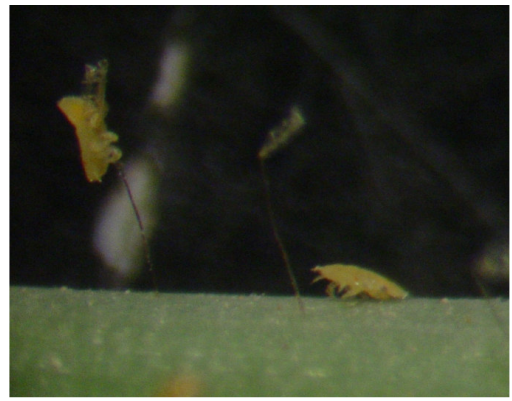

Fig. 8: Newly hatched nymph descending from the base of the egg

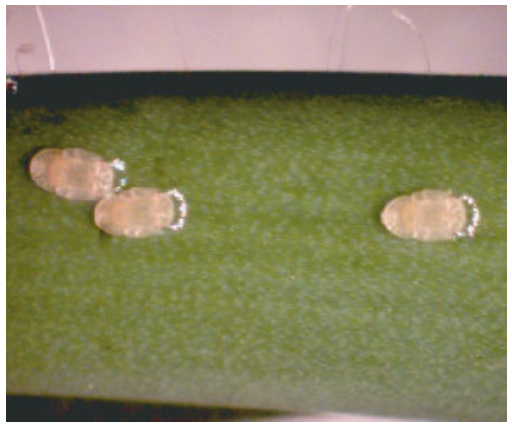

Fig. 9: Third instar nymphs established on the leaf
$625.5 \pm 53.9$, the daily pattern of oviposition is shown in Fig. 7. Egg incubation took 7.44 \pm 0.15 days and a mean of $90.3 \%$ eggs hatched. The newly hatched nymphs use the egg stalk to descend onto the leaf (Fig. 8). The nymphs passed through five instars before reaching the adult stage and the total development time for the nymphal stage as $17.71 \pm 0.61$ days. Figure 9 shows nymphs in the third instar. The sex ratio was estimated as $1: 1$.

\section{CONCLUSION}

The present study successfully fulfilled our research goals which were to clarify the unknown biological characteristics of a potentially new pest in onion fields. Although further studies should be undertaken but clearly these results will be invaluable as a basis for future control strategies of the pest in the context of integrated pest management programs.

\section{ACKNOWLEDGEMENT}

This study was supported by the Vice-Chancellor in Research Affairs of the Islamic Azad University. We also thank D. Burckhardt for confirming the identification of the psyllid.

\section{REFERENCES}

1. Annunziata, F., N. Clemente and P.D. Amora, 1980. Trioza tremblayi of onion. Informat. Ayrario, 36: 10161-10166.

2. Burckhardt, D. and P. Lauterer, 1997. A taxonomic reassessment of the triozid genus Bactericera (Homoptera: Psylloidea). J. Natural History, 31: 99-153. DOI: 10.1080/00222939700770081

3. HassanZadeh, M., 1996. Collecting and identifying insect fauna of onion fields in East Azarbaijan province of Iran. Agric. Sci., 6: 21-42.

4. Hodkinson, I.D., 1981. Status and taxonomy of the Trioza (Bactericera) nigricornis Forster complex (Homoptera: Triozidae). Bull. Entomol. Res., 71: 671-679.

5. Kazemi, M.H. and M. Mashhadi Jafarloo, 2007. Laboratory investigation of the biology of Bactericera tremblayi Wag. (Homoptera: Triozidae) a new pest in onion fields of Iran. In: Proceedings of the 16th International Plant Protection Congress, Oct. 15-18, British Crop Production Council (BCPC), Glasgow, UK., pp: 700-701.

6. Klimaszewski, S.M. and N. Lodos, 1979. Further data about jumping plant lice of Turkey (Homoptera: Psylloidea). Turkey Bitki Koruma Dergisi, 3: 3-16. 